International Journal of Social Research
(ISSN:2576-5531)

\title{
Tattoos, is it the new form of rebellion in China?
}

\section{Daniel Otero}

The Silver Beach International High School, Hui-dong Country, China

\begin{abstract}
When I first came to China, one thing tattoos were equated to: the mark of criminals, 'loose women' and gangsters. In other

${ }^{*}$ Correspondence to Author: words, tattoos equated with rebellion or bad boy/girl behavior. The stereotypes which go with it! This was back in 2009, as time transpired [at least a decade], it actually became a symbol of defiance within the young-College educated and professional generation; whether it was covered or not. This form of rebellion was a stand-up against everything which had been forced into them, since their childhood. Like the period of the 1960s in American counterculture, China in theory is going through the same thing: whether it's sexual exploration, homosexuality and now, tattoos. These are considered outside the norms and therefore, counterculture. It's my point to prove that the ink on the body is the new symbolism of rebellion. Spreading like literal wildfire throughout Mainland China. In a still conservative society, the young-College students and professionals of today are coming at odds with their parents and older generation. In this investigative paper, I aim to show the reader why! Therefore, taking people back in history, with examples like: Yueh Fei, when the tattoo was acDaniel Otero

The Silver Beach International High School, Hui-dong Country, China cepted and hopefully demonstrating with interviews/opinions that this trend continues to grow in China.

\section{eScîPub}

eSciPub LLC, Houston, TX USA.

Website: https://escipub.com/

How to cite this article:

Daniel Otero.Tattoos, is it the new form of rebellion in China? International Journal of Social Research, 2019; 3:32.

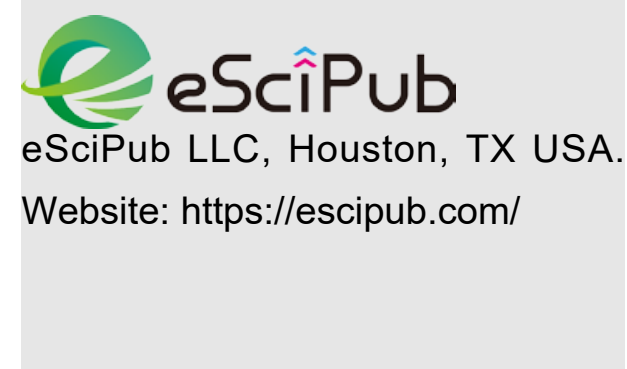

Keywords: Tattoo, criminals, 'loose women', gangsters, defiance, rebellion, counterculture, sexual exploration, College students, young professionals, homosexuality, ink, Yueh Fei and trend. 


\section{Methodology}

What began my experience with the tattoo world in China?

It actually began in Shaoxing, Zhejing Province. When I cruised into one of the alleys of this small-tourist city and desired a Buddha tattoo. Something to enhance my experiences and connections with life. Already carrying two-tattoos of my own. I wanted this third one to continue my journey. Painfully so, I paid my 600 RMB (\$87 USD in today's currency) and got approximately 90-minutes to two hours of torment with the young lady's rough-inexperienced-hand! The year was 2011 and since then, from the back alley-shadowy corners, I've seen the tattoo industry proliferate in China. Now, there's no denying that these businesses are coming out, front and center. The artist has moved to the forefront of the art world and into major cities. From the backstreets to the front-streets...

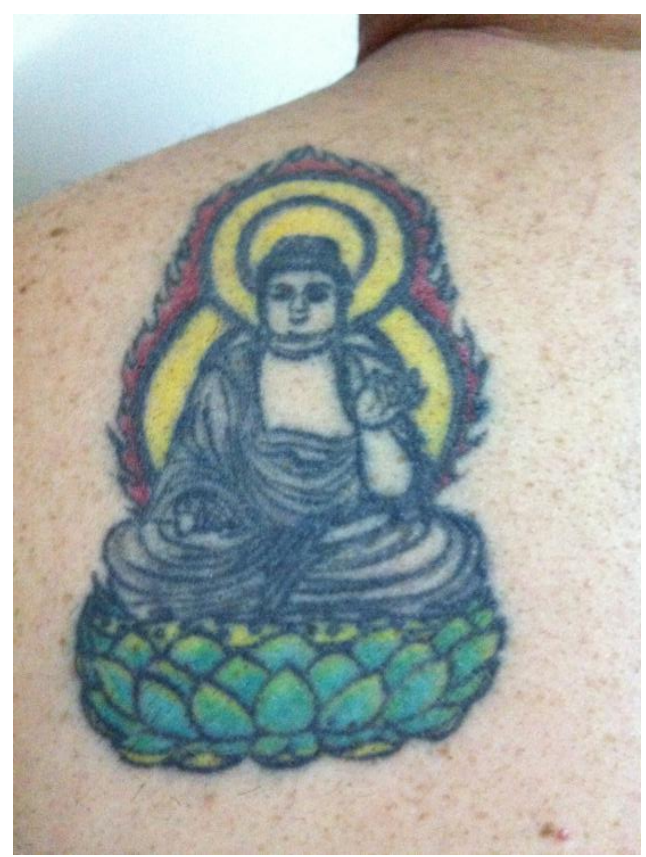

Photo by Rita Wei (Nanjing, Jiangsu, China)

Tattoos, the new form of rebellion in China?

Where have I seen the art get a foothold?

It grew in cities like: Shanghai, Beijing, Nanjing, Guangzhou, Hangzhou and Chengdu.
Conquering a new generation of young adults who wouldn't accept or conform to the old norms imposed by society.

Traveling through China, where I was most impressed with the tattoo world where in the cities of Shanghai, Nanjing and Chengdu.

Between my jobs as a freelance writer, columnist and journalist; I was able to do major stories on the topic at hand. But where I was most fascinated was in the city of Nanjing, Jiangsu Province. Here it literally exploded into a popular trend. Where I fell more in love with the art and wrote more than ever about it.

I wrote about the topic at first for the 'Nanjinger' (2011 - 2014) to give more exposure on why the young-College students and professionals were covering their bodies in ink. Exposing that a good majority of the customers in this city were young women (Otero, 2013).

Then, I did a second story for 'That's China' (Otero, 2013). Performing a touch-up on an old tattoo and the quality in the art. Focusing further on what were the popular symbols between men and women.

My third story was more about my fascination with the history of the tattoo in China; taking the hero and Chinese General in the Song Dynasty, Yueh Fei (Otero, n.d.). This one, I wrote for the Hangzhou Weekly (2011 - 2016) when the website was still in existence.

For a long time, I wanted to put something together. Something on the basis of an investigation [historical and social] to help outsiders; especially for those expats living in China and Chinese themselves. To help them understand what had changed in the image of the tattoo. Once considered a brand only for criminals, gangsters and prostitutes; now people in this traditional society were actually flaunting it [the tattoo] out in the open. 
What that said, I hope for those who read this investigative paper can understand further about the mysteries and whys of this art in China. Please enjoy!

\section{Introduction}

Tattoos began to gain momentum in China in the last 20 years. It was an instant desire or need to acquire, since it was considered taboo [at first] to have one and shameful for any family to have a child showcasing one.

With the changes in society, artist/singers/entertainers began to experiment using their bodies as a canvas.

It was like an 'about face', a 180-degree turn, from repudiation to want. It shifted from the criminal element to those leaving college and becoming career-oriented workers.

The tattoo became a symbol of sexuality and freedom in certain cities across China. Shops came about slowly, but surely. Where did the tattoo scene prosper mostly? Well, in Beijing, Shanghai and Guangzhou... The tattoo counterculture made its way through the backstreets of Nanjing and especially popular in cities like Chengdu, where it made literal leaps forward. The ancient capitals, for example, Hangzhou started to attract not only Chinese but foreigners to these tattoo scenes. It soon gained notoriety in smaller cities like Shaoxing, Zhejiang.

Areas in China which are prone to have plenty of newcomers and tourist, coming and going. What was once a mark for sex workers and mobsters, has now become part of the new norm (Liang, 2015).

But in this conservative country, is this kind of art accepted or easily dismissed with rejection? As with graffiti, it's a required taste. It cannot be denied, the 'taste' for this kind of art is certainly growing and there's no denying it!
In the following part, I'll explain a little about the history of the tattoo worldwide and how it developed in China. Showing how powerful a positive or negative image of the tattoo can certainly change people's perspective on something. From one thing which was once accepted in medieval times and inside the military community, to something totally denied as evil and pushed away.

History of the tattoo

For tattoos, the history began when kings and warriors began to mark their bodies. Whether it was by a count of their kills, words, a symbolism of leadership and what spanned through their lifetime.

The warriors' marks represented loyalty to his king, kin, tribe, ethnic group and country. Other warriors had different symbols to represent the number of kills in battle, etc.

Kings did the same when they came to power. It was to show through a permanent mark how a person could take such pain for his people, by scrolling these wonderful designs for all to see and read.

The conformation or the first recorded history of the tattoo goes back at least 12,000 years. This was the neolithic or 'new stone age' and human beings began changing from nomads and hunter gatherers to farmers/land dwellers.

In Ancient Japan it was all about finding the way, higher power or spiritual source. Before it became a symbolism of the Yakuza (Japanese gangsters) and sex workers, it was more about the element of spirituality and a person wore them to be closer to their gods (Hale, 2016).

It was confirmed through several digs and archaeological sittings that already people were commonly tattooing themselves through different cultures around the globe.

The markings on people were a form of Https://escipub.com/international-journal-of-social-research/ 
belonging and to unite the different

tribes. Principally in the countries like: Alaska (U.S.A.) with the Inuit tribes, across Western China, Mongolia, Greenland, Siberia, Egypt, the Philippines (Luzon), Sudan and Andes/Inca culture, Western-South America (Deter-Wolf, Robitaille, Krutak, Galliot, 2016).

When it comes to Europe, the discovery of 'Otzi the Iceman' in the valley of the Alps between Austria and Italy confirms how far tattoos went back in European society (Deter-Wolf, 2015). Estimating this finding around 6,000 years before.

The origins of the word tattoo

The word tattoo came into the English language by late $18^{\text {th }}$ Century, when the British expeditionary forces began an incursion into Polynesia and heard the Tahitian word of 'tatau' (Hine, 1876). It was later introduced by Cook's men into the English language. These sailors witnessed the symbolism and tattoos on the locals' bodies and from here the word began to change: from a steady-repetitive drumbeat to the art of decorating the body with ink.

Therefore, from Captain Cook's voyages the tattoo was reintroduced into Western society; however, the tattoo culture has always persisted in Europe since the time of the Ancient Greeks.

The greatest revival came by the 1960s, when it was in vogue and commonly used by artist.

The tattoo then went from a period of rejection to subsequent acceptance. But it would still depend on the person, society, country and culture in which one lived in.

\section{History of the tattoo in China}

For China, it is one of the oldest societies other than Egypt in the use of the tattoo. Tattoos were frequently found throughout Xinjiang Province, in Western China. This possibly took place because of the influences coming from Central Asian and Indo-European cultures.

During the Qing Dynasty (1636 - 1912), the practice of tattooing continued; although, it was sometimes considered a more barbaric/foreign practice (China Daily, 2011). In many ways, it is still that way in this rapidly changing society.

But for most who tattooed, there wasn't no middle ground, it was either one extreme or the other. Those who tattooed in the majority were either criminals or nationals, legends and displayed in folk tales as heroes. One thing which remained a constant till the early $20^{\text {th }}$ Century, was the tattooing of prisoners on the face with the Chinese character: 囚 ("Prisoner"). Slaves were also marked; however, only in rear instances (Chinese Tattoos, 2012).

More than that, this means for some Chinese traditionalist as the desecration of the body (Chinese Tattoos, 2012).

Tattoos have been a part of the Chinese culture and history for at least four to five-thousand years. Referred to as Ci Shen or Wen Shen, to 'puncture one's body' (Holiday Tour Guide, 2011). However, still considered by the older generation quite undesirable or unacceptable.

Needless to say, there is a growing trend among the youth of China accepting it. But the problem with it is the following, this desire has only been created by fashion and rebellion against the older generation, and nothing more. Because for those who get a tattoo, there is a deeper meaning, a symbolism. Almost one dealing with love, sentimentalism, pride for the country or to express life's experiences to say the least.

In Chinese history the person who always comes to mind is General Yueh Fei and the painful lesson taught by his mother: which was 
literally 'to never give up!'

But beyond the exotic, patriotic or curious nature of tattoos, in China these also had a sinister meaning. When it came to tattoos, a person who was convicted of a serious crime, such as murder, other than prisoners [which was mentioned before] were marked on the face with the characters of Ci Pei (Tattoo Exile) (China Daily, 2011). Literally like the 'mark of Cain', then they were ousted from their land and driven into exile.

China has 56 different ethnic groups. Out of the 56, three groups do practice culturally the art of tattooing: 1) Dai women often wear the tattoos on their hands, arms and eyebrows to accentuate beauty and the men on their muscles to express virility; 2) Du long (Drung/Derung) women started tattooing their faces 350 years ago to ward-off or in the prevention of being taken, raped or abused by foreign attackers; therefore, the custom still remains till this day; 3 ) For the $\mathrm{Li}$ group of females, since the age of 13 to 14 they begin the tattooing process along their necks, throats and face--after several years on the arms and legs, and when they get married on their hands. For the males, it's three-blue circles around the writs (Chinese Tattoos, 2012).

Extreme as it may sound, this is a cultural trend which continues; however, these traditions are little by little disappearing. Why? Since, more often than not, the new generation is moving away from the old traditions; as they become better educated, they'll move away into bigger cities to pursue their professional careers. Therefore, a lot of companies who hire young professionals do not allow any type of exposed tattoos. If this is the case, slowly, these traditions unless otherwise noted, will begin to die off, as the younger generation marks their path in the new and uncertain future of China.

And still, as these traditions disappear with minorities, other trends are gaining momentum and are 'full steam ahead'. A lot of the young guys, to mark their economical status and coming of age, get tattoos of tigers and dragons to state ferocity and strength!

Presently, the meaning of the tattoos acquired by those between 19 and 30 years old come to express something entirely different (Otero, 2015). The marks on the body are more about love, life, the essence of the human spirit and certain forms of spirituality, etc. Furthermore, this art is changing from negative to positive reviews and it's here to enhance contemporary-Chinese culture.

Notice carefully one thing, the art of tattooing, which had been believed in a stereotypical way to attract more males than females. Now, realize the changes in Chinese culture; how, as in the minority groups of China, females are getting attracted to this art and having it placed on their bodies.

One thing has changed from the medieval-military system in China.

Presently, service personnel aren't allow to have any type of tattoos or piercings on their bodies; this includes people in the government.

New Age Views \& Mainland-Chinese Opinions

For most in China, the dragon has a strong symbolism of power and strength (Hale, 2016). For others, it's the deep color red with yellow to represent patriotism. The most popular ones are the Chinese characters. Especially those which represent love, honor, loyalty and obedience. These embody hope.

Women will still enjoy the delicate parts of the tattoos through flowers and butterflies. But one thing is definitely a constant, males are attracted in greater numbers to the tattoo Https://escipub.com/international-journal-of-social-research/ 
throughout the majority of China. The biggest

difference is in cities, like: Nanjing and Chengdu. Possibly manifesting a degree of liberalism. And in truth, Chengdu is a liberal city; however, Nanjing is still quite conservative with the tattoo. Moreover, before I left the city, already tattoo parlors had begun to multiply and sprout all over Nanjing (Otero, 2017).

The following below were opinions [in their majority] given by the Chinese ' $X$ ', ' $Y$ ' and millennial generations in a town of Guangdong Province. A few others were either from Beijing, Jiangsu Province or Kansas City, Missouri (U.S.A.). Although, the former area of China has a large percentage of tattoo proliferation; but some views were from liberal, to in-between and conservative about this art. These individuals between the ages 15 to 43 years gave their impressions about the future of the tattoo in China:

For Ms. Song, she gave an interesting answer according to her traditions, "Tattoos are not a good thing for Chinese. I think because of the Chinese traditional-feudal thought.

Especially for teenagers...

They think you can't destroy the skin which your parents gave you at birth!"

In Ms. Nina Long's case, her idea was totally different, "In my opinion, I think tattoo is not a big problem nowadays. Because some of the tattoos are really beautiful and looks good! But I think some teenagers can have tattoos which are not too exaggerated, because they need to go to school and the exaggerated tattoos are not very suitable for High School students, I think!

But I think there are some teenager who get tattoos in an illegal way.

Because they think it's cool!

And in China, some older generations don't like tattoos.

They think, if you got tattoos, you are not a good person.

But I don't want to get one.

Because it is too painful," she ends with laughter in the background!

By the way, the age of consent in China for tattoos is 18; however, in a growing industry with little control. Some young people with money will get the art starting around 14 to 15 years of age.

Ms. Li Xiaoqin expressed, "Actually, I don't like tattoos very much.

I got a little tattoo on my arm a dozen years ago out of curiosity, but I don't really like it!"

For Mister David Huang, he wrote out an entire essay titled, 'Growth of the

Tattoo Parlours in China':

"Nowadays, the tattoo parlours in China are increasing. The increase is not without reasons. It is because, more and more teenagers are keen on putting tattoos on themselves. Some think of it as being cool, while others think of it as some kind of belief. Whether this or that, the demand for tattoos are rising, resulting in the increase of the tattoo parlours. From the get go, it has grown exponentially!

In the past, in China, not many people had tattoos on, because these were just not our doings. Putting tattoos on were not popular back then. However, for the past decades or so, as more foreign cultures had hit China, more and more things are being introduced or reintroduced into China and the tattoo was one of them.

Even though more people started to accept tattoos, there are still many people that do not like having tattoos. The process of putting 
tattoos on are just such a misery, hurts you right in the guts!"

Miss Cinci mentions her answer in an interesting way, "Tattooing in Chinese tradition has a very negative effect. It was being forbidden by law in Hong Kong some years ago for minors under the age of 18 to receive tattooing; which leaves a permanent and disfigured mark on the skin. Therefore, can hardly be described as an art form by Chinese culture. In fact, both Japanese (Yakuza) and Chinese (Black Society/Triads) mafia gang members use tattoos as a form of declaration, showing off and intimidating others. Tattooing is unhealthy and painful. It is a form of masochism. The pigment used contains lead, which is also poisonous. Back alley tattooist can spread hepatitis and aids, due to poor hygienic conditions.

My father taught me this when I was a child.

He's against tattoos. If I get a tattoo, he's going to 'kill' me," she ends with a sweet-smile and laughter!"

Another young gentleman, Mr. Wang Ziyi, who I transcribed his recorded answers, gave me his clever two-viewed perspective, "So, there's a saying in China, 'Your body comes from your parents!' It has a kind of meaning like, 'Your body belongs to your parents, your body is not actually yours!' And a, so you can't just change your body or like do something to it. And a, it is very very disrespectful if you change your body or do something to it. Like back, way back, like 1,000 or 5,000 years ago like, like even if you cut your hair; that is a huge, like that, that is very disrespectful to your parents. And a, even now, that the people who have tattoos like they have many-many limitations, of like finding a job. And a, I think that many people have their kind of, something like, ah, something like stereotypes. They think like the people with tattoos, like they are bad guys, gangsters or something like that. So, but for me and for my family, we accept tattoos. We think that tattoos, kind of stuff, a kind of way to express yourself; to like show others who you are or what's your personality. And a, in my opinion, tattoos is a kind of art. And a, I don't think it's anything bad! So, yep!"

Miss Yun Meiqi stated, "In my opinion, tattoo shows personal characteristics, whether good or bad, it's just like a special decoration.

In fact, I don't like tattoos which are over displayed!

I think permanent tattoos makes people awkward.

For example, 'I love my girlfriend so much, so I place her name on my tattoo.' Oh well, he may change to a new girl after a month and there's the need to 'eliminate' the tattoo," laughter comes from the statement!

"So, I like the tattoo which it can be easy to wash today and to draw another one tomorrow," end of comment!

Misses Wang Jun, a business professional and young mother said, "Oh, that's a very interesting topic. I had asked a similar question. People, they don't like tattoos because they think only bad people have tattoos. Because in Chinese history it leaves a special mark or tattoo is a method to carry the penalty of a crime. And tattoos had always been used by treasonous or heresy; people which caused the deaths for hundreds of innocent people, etc. And our body is from our parents, we should love it, as we love our parents... People who like tattoos, because that's an expression of their beliefs, or something or people who want to remember all the time. I am the first to accept!"

Miss Moye Li, High School student broke down Https://escipub.com/international-journal-of-social-research/ 
her views into several answers, "Tattoo is often seen in China. People use tattoos to represent something, some people or just for fun.

Did you know a model named Rick Genest from Canada?

I answered, "No, I don't think so!"

"I will find some pictures for you later.

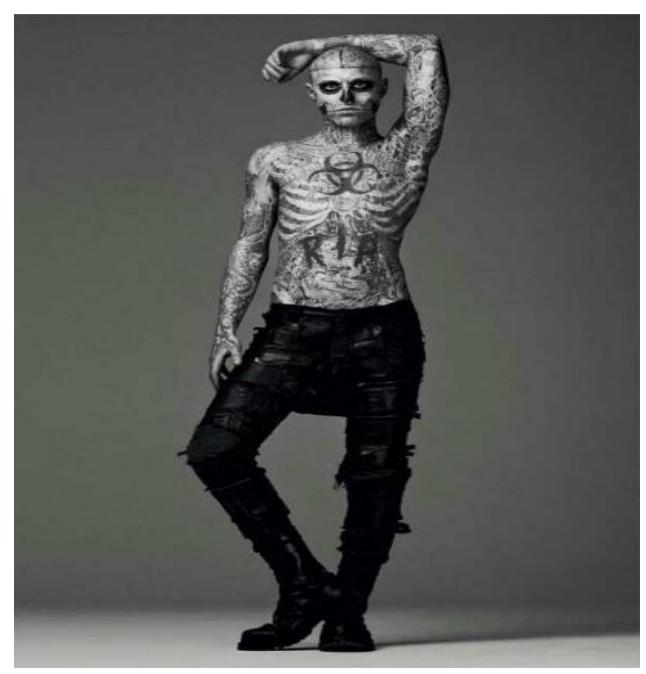

Photo from today.it (msn.com/en-us website)

But also there are tattoos just for fun or fashion...

If someone who tattoos all over their skin might scare others, they might be prejudiced! Most people don't want to be stared on the street everyday.

I answered, "At least, I don't!"

"I think people want to show others something deep in their heart, but they don't know how to speak to others. Then, they tattoo on their skin, small and simple picture or word can be seen, that they are expressing something carefully.

I have never seen someone tattoo all over their body in China. Most people like a small picture, or word.

It might be more popular than the real tattoo in China, you know.

Or do you know tattoo sticker?

I answered, "I know henna ink!"
"I'm not sure whether it can be a comparative example for you."

I concluded, "Yes, it is!"

Ms. Lucy Liu, Psychologist defines what she believes tattoos are all about, "Except historical and cultural reasons, I think that tattoos have three characteristics: 1. Highlighting their own special, unique nature, in order to attract other people's attention. 2. Have encountered some sad or nostalgic things to commemorate. 3. Low self-evaluation, low self-worth, low-self esteem, through external decoration to enhance their self-confidence."

Miss Yun Meiqi, a young-teacher in Beijing mentioned about her thoughts on tattoos and her experiences with me when she was my student at Nanjing University of Finance \& Economics, "Tattoos are a novel and distant thing for me. Maybe nobody around me has ever had a tattoo, so as long as people have tattoos, I think they're cool!

But I still remembered when you pricked my hand with a ballpoint pen and told us not to tattoo if we couldn't stand the pain. Actually, I really felt the pain."

These were the answers from Johnny Sun (a former colleague of mine) and his students, "Hey Daniel, here are some of the oral and written comments from different aged Chinese people's opinions and attitudes towards the tattoo:

----Moreover, it is getting more and more popular among Chinese people to have tattoo...

----When I got my first tattoo (a design on the inside of my forearm) many of my colleagues took interest. There were many raised eyebrows, but mostly they asked the normal questions, I.E. did it hurt? How long did it take? and so on.

----The reason for this is that a tattoo as a Https://escipub.com/international-journal-of-social-research/ 
criminal brand. Still is, really. In Japan people will get refused entry to places because they are tattooed. In HK certain elements have tattoos as a criminal clan marking, same as the Yakuza really. In the mainland tattoos are rebellious symbols... 'Look at me, aren't I daring?' So, girls who get tattoos are rebellious and not 'nice', guys who get tattoos are dangerous (or wannabe gangsters).

----The first image of tattoo in China appeared to be the exaggerating style in gangsters from some Hong Kong fighting movies about 30 years ago. Nowadays, the style is getting cute and it's mainly taken by adventurous youth or people in the arts profession. People in China are getting open and normally would accept seeing others with a tattoo, but not choose to have one on themselves. To have a little tattoo is fairly okay at work, while a tattooed full arm will raise eyebrows.

----Tattoo is more like a sub-culture in China. People don't like tattoo is because that tattoo always reminds them something related to crime, and tattoo was used to mark criminals by Chinese officials a thousand years ago, and it was a sub-culture as well. In current China, people have tattoos are officially not allowed to join the army still."

Mister Cyrus (Jia Chen), a former student of mine answered, "I think tattoo is fine, it may not be widely accepted before in China, but more and more young people are considering it a symbol of being fashionable."

Mister Eric Zou, a teacher expressed, "Wow, it is a very interesting topic. Actually, I can't say I like or hate it because a tiny and exquisite one does make someone look more charming; however, a whole arm fully with tattoos is not appreciated. Em... I would say having a tattoo is far more acceptable to me or other people in my age group, than elders like my parents and the person with tattoos will never be regarded as a gangster anymore to young people; but there is still a stereotype for elders." Miss Gu Jieni, a student in her teens added, "In my impression, tattoos are popular among young people in China, because they are influenced by some Western culture. In ancient China there were also some stories about tattoos. I think tattoo is not a bad thing, but maybe some more traditional families will not allow family members to get tattoos, many old people still think that only bad people get tattoos, and many young people are more willing to accept new things; which is why there will be some ideological differences between the young and old."

Mister Di, an English teacher had an entirely conservative answer to the reality faced in China, "In my opinion, its meaning is not good. Mostly, it stands for the gangsters, or sometimes rude men. If youngsters get tattoos, they will be taken as problem.

For the public, tattoos are not accepted.

For schools, students are not allowed to wear tattoos."

For Mr. Pan Bo, although, he gave the standard answer in the beginning, but his end was enlightening, "About tattoos, people usually think they are bad guys when they find they have some tattoos on their bodies.

But in these few years they changed a lot!

The people who are born and grow-up in China some years ago, they just don't want to see too many foreign countries' things appear on their children."

Chloe Ye, presently one of my students in the $11^{\text {th }}$ grade stated, "I think everyone has the right to choose what they like. As for me, I should Https://escipub.com/international-journal-of-social-research/ 
never get a tattoo. But I can't accept people getting tattoos on their faces. I think it's scary! And it will definitely have an impact on his/her career. My parents are more traditional and they wouldn't like me to get a tattoo."

Mister Chen Xingyu reflected more on his desire to get a tattoo based on his name and coming birthday, "A long time ago, I saw it for the first time in some movie.

The gang had tattoos.

So some people have the impression that tattoos are bad!

But young people have no such impressions now.

My Chinese name is Chen Xingyu.

Xing is star, yu is universe.

I'll be 18 next month.

I will have my first tattoo."

Mister Chi Mu lingshuang is a High School teacher who reflects on Chinese history and the tattoo, "Due to the very long history of Han, nearly 5,000 years, we considered the tattoo as an extremely insulting form and I believe that it is the thought still held by most people of the Han. You know that we had a kind of punishment, tattoo the criminals in ancient times.

But for lots of minorities, they have the habits of tattoos.

The young people (ages of $10 \sim 30$ ) in China usually have the same thought as their parents and the opinions by the government about the tattoo: tattoo $=$ the underworld. If you get a tattoo on your body, which is found by others, the school or your company will force you to leave.

That is the whole impression of tattoos given by the parents, teachers and other officers in the government.
But for my wife and I, we think tattoo is just a way of life, it expresses how free you can be. So, I don't think tattoo is a bad thing.

A little long story, I hope that could be helpful."

Kelly Xu gave a passionate answer on how she felt about tattoos and her future beloved, "Personal opinion, I do not mine others having tattoos. But for me, I do not want it. Also, I do not want my bf to have this neither.

Also, if I meet a strong man with it, I would feel afraid.

I meant a stranger...

Actually, it depends on the situation or personal emotion, I guess."

Jeanie Luo expressed, "My impression: I think tattoo is a thing that some teenagers or young adults want to try and they think it is an art. But I think tattoo is a very harmful thing.

Because I think it is too hurtful and the tattoo is something like paint(?)"

Mister Chen Haoran made his point of view by saying the following, "You ask me my viewpoint of view about the tattoo?

I answered, "Yep! What's your opinion, positive or negative?"

"I think to have tattoos isn't bad.

In fact, I want to get a tattoo when I am an adult.

Tattoo just is tattoo.

But, I don't know so well about tattoos."

Miss Zhao Yiran said, "Eemm, about tattoo...

I said, "Yes! Whatever you can tell me, good or bad."

"I don't think it's a very bad thing.

Cos nowadays...

Tattoos are just a hobby.

Someone has a tattoos doesn't mean they're a bad person. 
Some of my friends also have small tattoos too.

But they are good girls!

U know that!"

"Yes, I know that," I answered.

"Like some people get cartoon tattoos on their bodies, hhhhhh!

Tattoos mean you're a cool guy!

Hhhhhhh!"

Derek, a School Administrator in Guangdong Province mentioned, "It's not for my family or neither for me!"

Tattoos in China is usually a symbol, he or she is a member of a gang. Or used to be...

I do not know much about foreigners. But, I think they wanna express something from it and usually it is quite implicit!"

For Candy, a Chinese-High School arts teacher, she spoke in her own subtle way (transcribed answers), "Hello Daniel, I have tattoo and I like!

The good part it means something to me.

But I think people should make sure they want it, em because if they em recover (she meant remove) it because it is very difficult and painful. I don't like teenager people make tattoo."

Winston Wen, one of my students explains and broke down his answers, which I transcribed, "My opinions to tattoos are not very good, because when I was a child my mother and father always told me, don't make any tattoos on your fingers or in your body.

In some particular jobs: em like police man, doctors, and eh teachers and bosses of these positions they will not require (he meant, will not hire) the guy who has tattoos. And, eh, em, I think most-most of Chinese will have discrimination against tattoos.

However, when I'm walking-walking in the streets in England, I saw many guys with tattoos and em there are some shops like, em tattoo shops and they will-they will sell some tattoos. And em, the business is very good!

I mean if the foreigners have tattoos, I will think is very normal. But, em if, if, if there are some Chinese with tattoos, I think is very unusual.

Personally, I think it eh, depends in your education levels. Em, if you are, if you are in low education levels, em, I think you will make tattoos in your body and fingers. But if you have higher education levels, high education levels, you will not have it!"

For Mister Danny Gan, an Economics teacher, he reflected his position on the middle ground of this growing phenomena (answers were transcribed), "Hi Daniel, thank you for you emphasize on my opinion. I mean... You want to listen my opinion. So, for my personal view, the tattoo is neither good nor bad. So, I' $m$ in the middle side. Em, there are more and more Chinese people; especially young people they want to have a tattoo on their body. Some people they have tattoo just for, I think for beauty, for cool! Eh, for some people, they have their own tattoo for special meaning, for personal meaning. So that's my opinion!"

Miss Winnie Chen emphasized her point of view in a short article titled, 'Tattoo parlours in China': "Many years ago, before I was born, tattoo in China was not acceptable and people discriminated against a person who wore the art.

If you ever meet somebody on the streets with big tattoos, he or she may be a gangster. This stereotype sometimes still exist, but not so much now. It is more the thought of the older generation.

With the development of globalization, Chinese become more and more open-minded to people with tattoos. People get tattoos, not because 
they like it, but may try to hide some ugly scars on their bodies. More and more young people want tattoos because they consider it a symbol of being rebellious. For these reasons, people may also get tattoos with their favourite quotes, etc.

For the above, there's an increasing number of tattoo parlours in China. Most parlours used to be a small shop at the corner or back alley road where customers went there secretly! Now, these are bigger and bigger, brighter and brighter! Artists even advertise their shops on social media. They post beautiful and creative tattoos on the 'Weibo' platform to attract potential customers. (Furthermore, the staff used in these businesses is attractive... you know.)

In my opinion, I love the way they spread different cultures in my country. Citizens are cool with it and I hope in the future, there will be less and less prejudice towards those wearing tattoos.

I personally won't get a tattoo because it is too painful!" end of article.

Miss Miko Wu, a young lady from Mainland China who now works in Kansas City, Missouri answered my question in a simplistic fashion, "I do not have a strong feeling for tattoo. If it's just a small tattoo, I think that's super cute. But I don't like the kind of tattoo that covers up the whole body!"

Most of the answers and opinions accumulated were through the we-chat system and classroom environment in China between the dates $4^{\text {th }}$ and $11^{\text {th }}$ of January, 2019. Keeping in mind that the people who spoke did their best (thanks to them). Given the fact that is wasn't their first language. That's why, some answers were transcribed as it was stated or written down with mistakes. But all who participated did greatly and to the best of their abilities. For the young people who answered, their answers were in a three way split, those with tattoos were either: cool, criminals or in between (not for nor against).

The contemporary growing trend

The problem with getting tattoos in China can occur when a person becomes a soldier, teacher or doctor. In these three careers, it's a taboo and in the military it isn't accepted at all. You'll be shunned or ostracized at any chance of enlistment. For foreigners in China who do any teaching or doctoral work, it's more acceptable; since the foreigner comes from Western countries.

However, for some [Chinese] who got tattoos before they entered fully into their professions, they are now rethinking this trend and wanted to eliminate their body ink.

This example is often the reality manifested when young professionals are doctors and then, decide to remove the tattoo via laser treatment. The mark of the tattoo is never gone completely; therefore, a scar shall always remain.

With tattoos, it is literally 'till death do us part!' While interviewing an English teacher, Oscar Ma on November 23, 2018 in Guangdong Province. He gave his concerns, desires and perspectives on the tattoo in China and abroad:

He explained that he had a former classmate with two tattoos, one on the arm and the other on the hand. Oscar's friend decided to become a doctor, and here is where the problem arose.

Because in China this decision to get a tattoo, even when it happens recently, it is still controversial. Moreover, imagine when having to remove it!

Therefore, he decided to remove the visible 
ones. But traces were left with the scarring.

Oscar mentioned, "For me, it arose a deep interest and curiosity! I like to watch this show 'Tattoo Artist - America'; because I want to know the different styles." he continued, "I learned about the Japanese and Army tattooing. These were my interest; especially, those which centered on American cartoons."

Oscar gave examples when he spoke about the 'Looney Tunes' characters: Bugs Bunny, Elmer Fudd and Daffy Duck.

As he continued with the topic, thinking about the sketches; while the body was used as a canvas.

He carried on, "I watch the show, 'Tattoo, Ink!". I went on to ask him, "Are you willing to get a tattoo?"

His eyes lit-up with want and desire, but then turned away from the idea, "No, sadly it's a taboo for professionals; especially those whom are doctors and teachers! It isn't allowed for government workers in China or commercial-airplane crews. The biggest issue is that, if people see you with them and you're Chinese, you could easily be reported to your supervisors and fired!"

He expressed that for most Chinese, those whom are from the older generation will consider those wearing tattoos criminals; the thought is, cartoons are considered bad or a segment of evil.

I asked Oscar, "When were tattoos acceptable, then?"

He was direct, "China is a conservative nation; however, it was during the

Song Dynasty and the period of Yueh Fei when there wasn't the stigma of having ink on the body. It was important for warriors to show their patriotism to their leaders and country!
"How is this topic exposed in the media?", I had to ask.

He thought for a moment and said, "Do you know bilibili.com?"

I looked into his eyes and said, "Yes!"

As he continued, "There is an internet personality or reality star called, '凡 ze' (Fan ze in pinyin). She shares her experiences on a daily basis about covering every centimeter of her body in tattoos. Call it her passion or addiction. But on the other hand, tattoos are still stereotyped and closely thought as something nefarious or a person is into gangster activities. That is why I don't have nothing colored on my skin. How people treat me it is still way too important than what's in fashion at the time. Plus, there would be a lot pressure against me; therefore, I don't dare!"

This was when, as we spoke, he thought about a documentary he had seen on the BBC network back in the U.K. (United Kingdom).

Oscar mentioned about this study, "Even when the U.K. is an liberal/open society, you still had people whom are reserved or against the tattoo artistry. There was this show I watched about a young man whose body is covered in tattoos. In the experiment, when he asked for help, nobody would come and aid him! However, when he wore a long-sleeve shirt and covered-up his tattoos

and asked for help, there were several people who assisted him! Surprising, right? The U.K. as an open culture, but people still regarded tattoos as something bad!"

It was all about appearance when walking down the street!

For Oscar, there are limits when getting tattoos or there ought to be limits and not overdo it! What intrigued or bothered him the most [and it wasn't something he ever wanted to emulate], Https://escipub.com/international-journal-of-social-research/ 
were the scary pictures in the tattoo world. This behavior or these types of artistic desires he couldn't agree with.

Oscar went on to conclude, "Because as responsible adults, we still live in a society which is basically conservative (when he referred to China). It is still a country that could easily reject and ostracize you for the way you look."

We both thought, it is changing in China. How? There are more people with tattoos, the young adults.

However, Oscar although showed interest, he thought it was better to not have this type of artistry at all.

I thought, it's okay to have bodywork [but as in my case] like in other peoples' cases who have tattoos (Chinese or foreigner) and are teachers, it's best to have the art covered/concealed for now till the rules/laws change!

But that is something which may or may not happen soon enough.

\section{Conclusion}

The love and hate relationship of thousands of years here in China won't go away anytime soon. But one thing was a constant, the growth of an industry which will not easily go away!

For many of those interviewed, the answers were standard. I would say that it was a three-way split in the way people either did-didn't accept tattoos or remained in the middle. For the most part, it was the majority of the teenagers who answered on the grounds of either getting one or not getting.

The answers were abound, but there was always a constant.

For Chinese, when they thought about tattoos, they reflected on their history.
For those who had conservative views, these were broken down into four points: our parents gave us our bodies-therefore, we shouldn't desecrate it; tattoos are bad and come from criminals/gangsters; a tattoo can be riddled with diseases; and tattoos cannot be worn by military personnel, government workers or teachers (However, in the latter, even that is changing; because some teachers in this study already had tattoos).

For the rest (liberal types), it was based on getting a tattoo that's in the following three: a tattoo is fashionable, it represents a belief/freedom and indicates a special moment in a person's life. It wasn't rebellion, but a trend!

With these statements, I conclude this study. And can factually say, tattoos will continue to grow, as the People's Republic of China continues to open up.

\section{Abbreviations}

The following abbreviations are in the order in which these appear:

[1] RMB (or CNY - Chinese Yuan Renminbi) Renminbi or Yuan, the Chinese national currency

[2] USD - the U.S. dollar in the world currency trade

[3] N.D. - No Date

[4] U.S.A. - United States of America

[5] I.E. - id est (that is)

[6] U.K. - United Kingdom

[7] BBC - British Broadcasting Corporation

[8] P.R.C. - People's Republic of China

\section{References:}

1. China Daily. (March 15, 2011). "A history of the Chinese tattoo and Chinese tattooing traditions". Retrieved from 
http://www.chinadaily.com.cn/life/2011-03/15/cont ent_12175139.htm

2. Chinese Tattoos. (December 12, 2012). "History of Chinese Tattoos: Long history of Chinese Tattoos. Retrieved from

www.chinesetattoos.org/history-of-chinese-tatto os

3. Deter-Wolf, Aaron. (11 November 2015). "It's official: Ötzi the Iceman has the oldest tattoos in the world". RedOrbit.com.

4. Deter-Wolf, Aaron; Robitaille, Benoît; Krutak, Lars; Galliot, Sébastien. (February 2016). "The World's Oldest Tattoos". Journal of Archaeological Science:

Reports. 5:

19-24.

5. Hale, Richard R. (December 13, 2016). "Dragon Tattoo Ideas, History, and Meaning:

Chinese and Japanese Designs". Tat Ring. Retrieved from https://tatring.com/tattoo-ideas-meanings/Dragon -Tattoo-Ideas-And-Meanings-

Chinese-and-Japanese-Dragon-Tattoo-HistoryAnd-Meaning\#

6. Hine, Thomas Chambers (1876). "Nottingham: its castle: a military fortress, a royal palace, a ducal mansion, a blackened ruin, a museum and gallery of art." London: Hamilton, Adams. p. Appendix.

7. Holiday Tour Guide. (September 19, 2011). "A History of the Chinese Tattoo and Chinese Tattooing Traditions". Culture $x$ tourism. Retrieved from

http://chinese.culturextourism.com/history-chines e-tattoos-chinese-tattooing-tr aditions/

8. Liang, Lu-Hai. (August 24, 2015). "Good girls, not gangsters?: Tattoos are no longer a taboo in China”. CNN. Retrieved from https://edition.cnn.com/style/article/china-tattoos/i ndex.html

9. Otero, Daniel. (May, 2013). "Dreams of Ink". The Nanjinger. pp. 16 - 17.
10. (September, 2013). "BODY WORK IN INK". That's China. Zhejiang. 18.

11. (n.d.). "Yue Fei's story and the tattoo". Hangzhou Weekly.

12. (July 20, 2015). "Trashing traditional tattoo stereotypes". Beijing Global Times Metro. Retrieved from http://www.globaltimes.cn/content/932891.shtml 13. (November 17, 2017). "Life's experiences tattooed on the body".

Future Handling Hong Kong. Retrieved from https://futurehandling.com/2017/11/17/tattoo-me-t attoo-you/

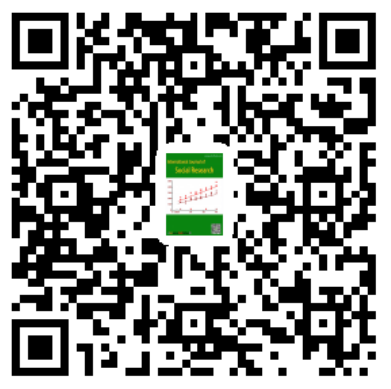

